\title{
Subcortical heterotopic gray matter brain malformations
}

\section{Classification study of 107 individuals}

Renske Oegema, MD, PhD, A. James Barkovich, MD, Grazia M.S. Mancini, MD, PhD, Renzo Guerrini, MD, FRCP, and William B. Dobyns, MD

Neurology ${ }^{\circledR}$ 2019;93:e1360-e1373. doi:10.1212/WNL.0000000000008200

\section{Abstract}

\section{Objective}

To better evaluate the imaging spectrum of subcortical heterotopic gray matter brain malformations (subcortical heterotopia $[\mathrm{SUBH}]$ ), we systematically reviewed neuroimaging and clinical data of 107 affected individuals.

\section{Methods}

SUBH is defined as heterotopic gray matter, located within the white matter between the cortex and lateral ventricles. Four large brain malformation databases were searched for individuals with these malformations; data on imaging, clinical outcomes, and results of molecular testing were systematically reviewed and integrated with all previously published subtypes to create a single classification system.

\section{Results}

Review of the databases revealed 107 patients with SUBH, the large majority scanned during childhood (84\%), including more than half before 4 years (59\%). Although most individuals had cognitive or motor disability, 19\% had normal development. Epilepsy was documented in $69 \%$. Additional brain malformations were common and included abnormalities of the corpus callosum (65/102 [64\%]), and, often, brainstem or cerebellum (47/106 [44\%]). Extent of the heterotopic gray matter brain malformations (unilateral or bilateral) did not influence the presence or age at onset of seizures. Although genetic testing was not systematically performed in this group, the sporadic occurrence and frequent asymmetry suggests either postzygotic mutations or prenatal disruptive events. Several rare, bilateral forms are caused by mutations in genes associated with cell proliferation and polarity (EML1, TUBB, KATNB1, CENPJ, GPSM2).

\section{Conclusion}

This study reveals a broad clinical and imaging spectrum of heterotopic malformations and provides a framework for their classification.

\author{
Correspondence \\ Dr. Oegema \\ r.oegema@umcutrecht.nl
}

\section{MORE ONLINE}

- CME Course

NPub.org/cmelist

From the Department of Clinical Genetics (R.O., G.M.S.M.), Erasmus MC University Medical Center, Rotterdam; Department of Genetics (R.O.), University Medical Center Utrecht, the Netherlands; Departments of Radiology and Biomedical Imaging and Neurology and Neurology (A.J.B.), University of California, San Francisco; Department of Neuroscience, Pharmacology and Child Health (R.G.), Children's Hospital A. Meyer and University of Florence, Italy; Center for Integrative Brain Research (W.B.D.), Seattle Children's Research Institute; and Departments of Pediatrics and Neurology (W.B.D.), University of Washington, Seattle.

Go to Neurology.org/N for full disclosures. Funding information and disclosures deemed relevant by the authors, if any, are provided at the end of the article. 


\section{Glossary}

ACC $=$ agenesis of the corpus callosum; HET = heterotopic gray matter brain malformations; $\mathrm{MCD}=$ malformations of cortical development; $\mathbf{O F C}=$ occipital frontal circumference; $\mathbf{P N H}=$ periventricular nodular heterotopia; $\mathbf{S B H}=$ subcortical band heterotopia; SUBH = subcortical heterotopia.

Malformations of cortical development (MCD) comprise a large group of disorders resulting from defects in formation of the cerebral cortex that involve all major stages of cortical development including neurogenesis, neuronal migration, and postmigrational development. ${ }^{1}$ MCDs collectively place a substantial burden on health care and society, as they account for $3 \%$ of intellectual disability, $25 \%$ of pediatric focal epilepsy, $5 \%-15 \%$ of adult epilepsy, $20 \%-40 \%$ of therapyresistant epilepsy, and $42 \%$ of children undergoing epilepsy surgery. ${ }^{2-6}$

The increasing availability and resolution of MRI technology and molecular genetics over the last 30 years has resulted in a classification describing more than 200 different types of MCD. ${ }^{1}$ Several of these are currently classified as gray matter heterotopia, clusters of neurons derived from neurogenesis in the ventricular or subventricular zone but unable to migrate to their normal position in the cortex (heterotopic gray matter brain malformations [HET]). The most commonly encountered heterotopia are found as nodules along the walls of the lateral ventricles (periventricular nodular heterotopia $[\mathrm{PNH}])$. In contrast, the more rarely identified subcortical heterotopia (SUBH) is located within the white matter, between the cortex and lateral ventricles. The nomenclature used for even the most common of these has not been consistent, and includes giant, curvilinear, nodular, focal, and massive heterotopia. ${ }^{1,7-14}$ Several others have been classified as rare subtypes of polymicrogyria. ${ }^{15,16}$

While analyzing imaging studies of individuals with brain malformations predominantly characterized by heterotopic localization of gray matter, we observed far more diversity than previously reported. This group of MCD includes several types of SUBH as well as several complex MCD composed of sulci that extend deeply into the subcortical centrum semiovale. This led us to systematically search 4 large databases containing records on more than 10,000 patients with MCD based in Seattle, Rotterdam, Florence, and San Francisco for patients with these malformations. We identified 107 patients with MCD that extended deep into the subcortical white matter, grouped them based on shared imaging characteristics, and analyzed the neuroimaging and clinical features for each subtype.

\section{Methods}

\section{Subject selection}

We identified patients with HET by first searching a large Seattle database of patients with developmental brain disorders ( $\mathrm{n}=9,700$ participants). After defining many different patterns of HET, we searched 3 other MCD databases (Rotterdam, Florence, San Francisco) for patients with similar malformations. All patients were previously examined by or referred for MRI review to one of the senior authors.

All participants with any HET with gray matter visible in at least one region at a level where only white matter would normally be expected were evaluated, as long as sufficient imaging was available to perform a detailed review. Participants with subcortical band heterotopia $(\mathrm{SBH})$ or isolated $\mathrm{PNH}$ were not reviewed, as these are already well-described and classified. ${ }^{1,17-19}$

\section{Standard protocol approvals, registrations, and patient consents}

Institutional review boards of Seattle Children's Hospital, The University of Chicago, University of Minnesota, Erasmus University Medical Center, Tuscany Region of Italy, and University of California-San Francisco approved our inclusion of these patients in research studies.

\section{Clinical data}

We searched available clinical notes and referral information and, whenever possible, recontacted the referring physicians and parents or guardians. We sought a minimum dataset comprising age at first MRI, neurologic outcome, behavioral abnormalities, presence and age at onset of seizures, and head circumference (occipital frontal circumference [OFC]). Further data were noted when available in our records.

\section{Brain imaging}

All patients selected for review underwent at least 1 T1weighted (2D or volumetric) sequence and $1 \mathrm{~T} 2$-weighted sequence, and all underwent imaging in at least 2 planes. All available images were reviewed using a standardized approach by W.B.D. and R.O., with representative examples reviewed by all authors. We systematically assessed the location (bilateral symmetric or asymmetric, unilateral right or left; anterior, central, or posterior predominant, or diffuse; and recorded which lobes were affected), size including presence of mass effect on surrounding structures, morphology and general orientation, connection to the cortex and ventricular wall, and relationship to CSF spaces. Next, the imaging was scored for the presence and distribution of cortical malformations per se, separate $\mathrm{PNH}$, and any noncortical brain malformations, especially anomalies of deep gray matter structures, complete agenesis of the corpus callosum (ACC) and partial agenesis of the corpus callosum, diffuse cerebellar 
hypoplasia or vermis-predominant cerebellar hypoplasia, and Dandy-Walker malformation.

\section{Literature search}

To establish a comprehensive classification, we searched for publications of HET subtypes in PubMed, limiting our search to the English language literature with publication dates between January 1985 and December 2015, and used key words including "subcortical heterotopia," "heterotopia and brain," "brain-in-brain," and "aventriculy."

\section{Statistical analysis}

Analysis was performed using IBM SPSS Statistics software v21 (IBM, Armonk, NY). Frequencies and percentages were calculated to compare groups. To test for normal distribution, the Shapiro-Wilk test was used. To compare characteristics between groups, the $\chi^{2}$ test and Fisher exact test were used (for groups larger than 10). The Kruskal-Wallis rank-sum was used to compare the age at presentation and age at seizure onset among groups. The nonparametric Mann-Whitney $U$ test was used to compare seizure onset (age) with bilateral presence of HET. When information on a given feature was not available, the patient was excluded for analysis of that feature.

\section{Data availability}

For each individual, all relevant clinical data and the results of the systematic MRI reviews were entered into an anonymized Excel spreadsheet (MRI reviews; doi.org/10.5061/dryad. tq70kt3). The MRI are stored at the Dobyns Laboratory.

\section{Results}

From 188 patients identified by database searches, we recognized 107 individuals with SUBH and sufficient imaging available for classification. Among 95 individuals with sex recorded ( 54 male, 41 female), mild skewing of the sex ratio was observed: $57 \%$ male to $43 \%$ female. Age at first MRI study was recorded for 83 individuals, and ranged from 2 days to 32 years but with significant skewing towards infancy and early childhood (mean 6.4 years, median 2.0 years, $p=1.5 \times 10^{-10}$ ). A large majority of participants were scanned during childhood (70/83 [84\%]), and more than half before age 4 years (49/83 [59\%]).

\section{Clinical features}

Clinical records are summarized in table 1 . Data regarding development were available for 68 individuals, and almost a fifth (13/68 [19\%]) had normal development. Most of those with normal development came to medical attention because of seizures. The majority had developmental and neurologic dysfunction consisting of early developmental delay, intellectual disability, learning difficulties, and motor defects. The severity varied from profound intellectual disability with no major developmental milestones reached to isolated motor or language delay. Behavioral abnormalities were noted for 17 of 44 (39\%) participants with data available. Most individuals had epilepsy (50/72 [69\%]) with age at onset from the neonatal period to 25 years, but significantly skewed towards infancy and early childhood (mean 7.3 years, median 4.5 years, $p<0.001$ ). Almost half $(32 / 69[48 \%])$ had a major malformation outside of the brain. The range of malformations was wide, with the eyes, limbs, and genitourinary system being most commonly affected. This included 3 cases with colobomas, 2 with micropthalmia, 3 with clubfoot, and 2 with unilateral reduction defect of the arm.

According to available medical records, most patients lacked a genetic or syndrome diagnosis. No pathogenic chromosomal abnormalities were found, although it is unknown how many had chromosome analysis or microarray performed. Single gene mutations in EML1, CENPJ, OFD1, and $T U B B$ were reported for 4 patients. A summary of genes associated with SUBH in this and in previous studies is shown in table 2 .

\section{Classification}

Our overall classification of MCD is based on the earliest embryonic stage at which the developmental process was first disturbed, dividing malformations into those involved with (1) abnormal proliferation of neurons and glia, (2) abnormal neuronal migration, and (3) abnormal postmigrational development. ${ }^{1}$ We have integrated the HET into this system (table 2), identifying 5 major groups (further described below). The most common pattern by far was curvilinear HET $(66 / 107$ [62\%]).

In addition to the HET, most patients had noncortical brain malformations involving the corpus callosum (65/102 $[64 \%])$, basal ganglia, thalami, or both (44/104 [40\%]), and cerebellum, brainstem, or both (47/106 [44\%]). For analysis of differences between groups, only the curvilinear and deeply infolded HET groups were large enough $(>10)$ to be selected for comparison. We found a significant difference in the abnormalities of the basal ganglia and thalami between these 2 groups ( $45 \%$ vs $0 \%, p<0.001$ ). The group of all participants with bilateral SUBH was also significantly enriched for extra-CNS malformations $(p=0.01)$, and mildly enriched, although not significantly, for abnormal development $(p=0.09)$. Unilaterality or bilaterality of heterotopia did not influence the presence or age at onset of seizures. Remarkably, all but one individual with normal cognitive development (13/14) had curvilinear HET.

\section{Group 1. Congenital microcephaly with premigrational reduced proliferation and variable additional MCD}

\section{1a. Nodular heterotopia in peritrigonal regions (optic pathways)}

All patients have borderline to profound ( $-11 \mathrm{SD})$ microcephaly. In addition, they show solid nodular HET situated in the region of the peritrigonal optic pathway posterior to the 
Table 1 Basic characteristics of all 107 individuals

\begin{tabular}{|c|c|c|c|}
\hline & All & Curvilinear (2c, 2d) & Deeply infolded (4c-4e) \\
\hline Total & 107 & 66 & 19 \\
\hline Male & $54 / 95(57)$ & $34(60)$ & $7(39)$ \\
\hline \multicolumn{4}{|l|}{ Age at first MRI, y } \\
\hline$<1$ & 25/83 (30) & $15(29)$ & $4(23)$ \\
\hline $1-4$ & $24 / 83(29)$ & $12(24)$ & $8(47)$ \\
\hline 4-18 & $21 / 83(25)$ & $15(29)$ & $3(18)$ \\
\hline Adult & $13 / 83(16)$ & $9(18)$ & $2(12)$ \\
\hline Epilepsy & $50 / 72(69)$ & $31(74)$ & $9(60)$ \\
\hline $\begin{array}{l}\text { Delayed } \\
\text { development/ID }\end{array}$ & $55 / 68(81)$ & $28(74)$ & $13(93)$ \\
\hline Abnormal behavior & $17 / 44(39)$ & $10(36)$ & $2(22)$ \\
\hline \multicolumn{4}{|l|}{ Head circumference } \\
\hline$<p 5$ & $18 / 45(40)$ & $5(24)$ & $5(50)$ \\
\hline$>p 95$ & $4 / 45(9)$ & $3(14)$ & $0(0)$ \\
\hline \multirow{2}{*}{$\begin{array}{l}\text { Extra-CNS } \\
\text { malformation }\end{array}$} & $32 / 69(46)$ & $14(34)$ & $7(58)$ \\
\hline & $\begin{array}{l}\text { Clubfeet (2), laryngomalacia (2), hearing } \\
\text { loss (2), underdeveloped genitalia, pelvic } \\
\text { kidney, HPE stigmata (2), esotropia ( } 2 \text {, } \\
\text { microphthalmia, coloboma, cataract, } \\
\text { epidermal nevus scalp, aplasia cutis + } \\
\text { skin tag scalp, cleft palate, absent and } \\
\text { hypoplastic digits, radioulnar synostosis } \\
\text { with short radius, polydactyly, edema }{ }^{a}\end{array}$ & $\begin{array}{l}\text { Heart defect (3), limb reduction defect } \\
\text { (2), polydactyly (2), clubfoot, limb } \\
\text { hypoplasia, scoliosis, microphthalmia, } \\
\text { coloboma, optic nerve hypoplasia, } \\
\text { frontonasal dysplasia, renal cysts, UPJ- } \\
\text { stenosis, underdeveloped genitalia }\end{array}$ & $\begin{array}{l}\text { Cutis aplasia/abnormal scalp skin (2), } \\
\text { severe esotropia, coloboma, hearing } \\
\text { loss, underdeveloped genitalia, urinary } \\
\text { reflux, spine malformation, } \\
\text { micrognathia, jejunal atresia }\end{array}$ \\
\hline \multicolumn{4}{|l|}{ Imaging } \\
\hline Bilateral SUBH & $67 / 107(63)$ & $34(52)$ & $17(90)$ \\
\hline PNH & $53 / 98(54)$ & $42(69)$ & $6(38)$ \\
\hline \multicolumn{4}{|l|}{ Abnormalities } \\
\hline Corpus callosum & $65 / 102(64)$ & $40(64)$ & $12(63)$ \\
\hline $\begin{array}{l}\text { Basal ganglia and } \\
\text { thalami }\end{array}$ & $42 / 104(40)$ & $29(45)$ & $0(0)$ \\
\hline $\begin{array}{l}\text { Cerebellum/other } \\
\text { abnormality in } \\
\text { posterior fossa }\end{array}$ & $47 / 106(44)$ & $26(40)$ & $5(26)$ \\
\hline
\end{tabular}

Abbreviations: ID = intellectual disability; $\mathrm{PNH}=$ periventricular nodular heterotopia; $\mathrm{SUBH}=$ subcortical heterotopia.

Values are $\mathrm{n}(\%)$.

${ }^{a}$ Not including malformations listed in the $2 c, 2 d$, and $4 c-4 e$ groups.

deep gray nuclei (figure 1). This pattern has been associated with TUBB, KATNB1, and CENPJ mutations. ${ }^{20,21}$

\section{Groups 2a and 2b. Diffuse cortical and subcortical dysgenesis}

\section{2a. Diffuse ribbon-like heterotopia}

This malformation consists of megalencephaly with a distinct ribbon-like HET that consists of a bilateral and symmetric single continuous, undulating ribbon-like layer of gray matter located in the frontal, parietal, and occipital lobes with no visible connection to the overlying cortex (figure 2). The absence of veins and CSF-like spaces distinguishes this malformation from the curvilinear and deeply infolded subtypes. The cortex appears diffusely thin and dysplastic with shallow sulci. Other features include prenatal-onset ventriculomegaly or hydrocephalus and ACC. This is a rare malformation with only 3 families previously published, including a patient from this study, and has been associated with biallelic mutations in EML1. ${ }^{22,23}$ 
Table 2 Classification of heterotopic gray matter brain malformations (HET)

\begin{tabular}{|c|c|c|c|c|}
\hline & Group & Total & Cause & $\begin{array}{l}\text { Barkovich } \\
\text { et al. }{ }^{1} \text { (2012) }\end{array}$ \\
\hline 1 & $\begin{array}{l}\text { Congenital microcephaly with premigrational } \\
\text { reduced proliferation and variable additional } \\
\text { MCD }\end{array}$ & & & I.A \\
\hline $1 a$ & $\begin{array}{l}\text { Nodular HET in peritrigonal regions (optic } \\
\text { pathways) }\end{array}$ & 05 & Biallelic mutations in CENPJ, TUBB, or KATNB1 & \\
\hline $2-1$ & Diffuse cortical and subcortical dysgenesis & & & I.C \\
\hline $2 a$ & Diffuse ribbon-like HET & 02 & Biallelic mutations in EML1 & \\
\hline $2 \mathbf{b}$ & $\begin{array}{l}\text { Mesial parasagittal HET, Chudley-McCullough } \\
\text { syndrome }\end{array}$ & 02 & Biallelic mutations in GPSM2 & \\
\hline $2-I I$ & $\begin{array}{l}\text { Multifocal or focal cortical and subcortical } \\
\text { dysgenesis }\end{array}$ & & & I.C \\
\hline $2 c$ & $\begin{array}{l}\text { Curvilinear HET with CSF-like spaces (unilateral or } \\
\text { bilateral) }\end{array}$ & 61 & & \\
\hline $2 d$ & $\begin{array}{l}\text { Curvilinear HET with ACC-IHEM cysts (always } \\
\text { bilateral) }\end{array}$ & 05 & Heterozygous mutations in OFD1 & \\
\hline $2 e$ & Transmantle columnar HET & 03 & Unknown & \\
\hline 3 & $\begin{array}{l}\text { Malformations due to abnormal neuronal } \\
\text { migration }\end{array}$ & & & ॥ \\
\hline \multirow[t]{2}{*}{$3 a$} & $\begin{array}{l}\text { Malformations with neuroependymal } \\
\text { abnormalities: periventricular heterotopia (not } \\
\text { discussed) }\end{array}$ & NA & $\begin{array}{l}\text { Heterogeneous in etiology including chromosomal } \\
\text { aberrations (e.g., 6qter deletions) and single gene } \\
\text { mutations (e.g., FLNA) }\end{array}$ & II.A \\
\hline & $\begin{array}{l}\text { Malformations due to generalized abnormal } \\
\text { transmantle migration: subcortical band } \\
\text { heterotopia (not discussed) }\end{array}$ & NA & $\begin{array}{l}\text { Heterozygous mutations in } D C X \text { in females } \\
\text { (common), mosaic hemizygous mutations in } D C X \text { in males, } \\
\text { or mosaic or germline missense mutations in LIS1 (rare) }\end{array}$ & II.B \\
\hline 4 & $\begin{array}{l}\text { Malformations due to abnormal } \\
\text { postmigrational development with subcortical } \\
\text { or transmantle component }\end{array}$ & & & III.A \\
\hline $4 a$ & Schizencephaly (not discussed) & NA & Vascular disruption & \\
\hline 4b & Transmantle columnar and fan-like HET \pm clefts & 02 & Vascular disruption & \\
\hline $4 c$ & Deeply infolded HET_-parieto-occipital region & 10 & Unknown & \\
\hline 4d & Deeply infolded HET_parasagittal region & 06 & Unknown & \\
\hline $4 e$ & Deeply infolded HET_other regions & 03 & Unknown & \\
\hline 5 & HET with bilateral complex patterns & & & NA \\
\hline $5 \mathbf{a}$ & Microventriculy with HET (holoprosencephaly-like) & 02 & Unknown & \\
\hline $5 b$ & Brain-in-brain malformation & 04 & Unknown & \\
\hline $5 c$ & Complex chaotic HET & 02 & Unknown & \\
\hline
\end{tabular}

Abbreviations: $\mathrm{ACC}=$ agenesis of the corpus callosum; $\mathrm{IHEM}=$ interhemispheric; $\mathrm{MCD}$ = malformations of cortical development.

\section{2b. Mesial parasagittal heterotopia, Chudley- McCullough syndrome}

This syndrome is characterized by sensorineural hearing loss and specific brain anomalies. Most individuals have a recognizable pattern of HET extending along the mesial aspect of the lateral ventricles, with direct connection to mesial polymicrogyria-like cortex at the anterior and posterior limits of the heterotopia (figure 2). A separate HET of similar morphology is present in the temporal lobes. In addition, cerebellar dysplasia, corpus callosum abnormalities, and arachnoid cysts are often present. It is caused by biallelic mutations in the GPSM2 gene. ${ }^{24}$

\section{Groups 2c-2e. Multifocal or focal cortical and subcortical dysgenesis}

\section{2c. Curvilinear heterotopia with CSF-like spaces}

Curvilinear heterotopia with CSF-like spaces were present in 61 patients, forming the largest group in our cohort. These malformations are usually large, occupying one or 


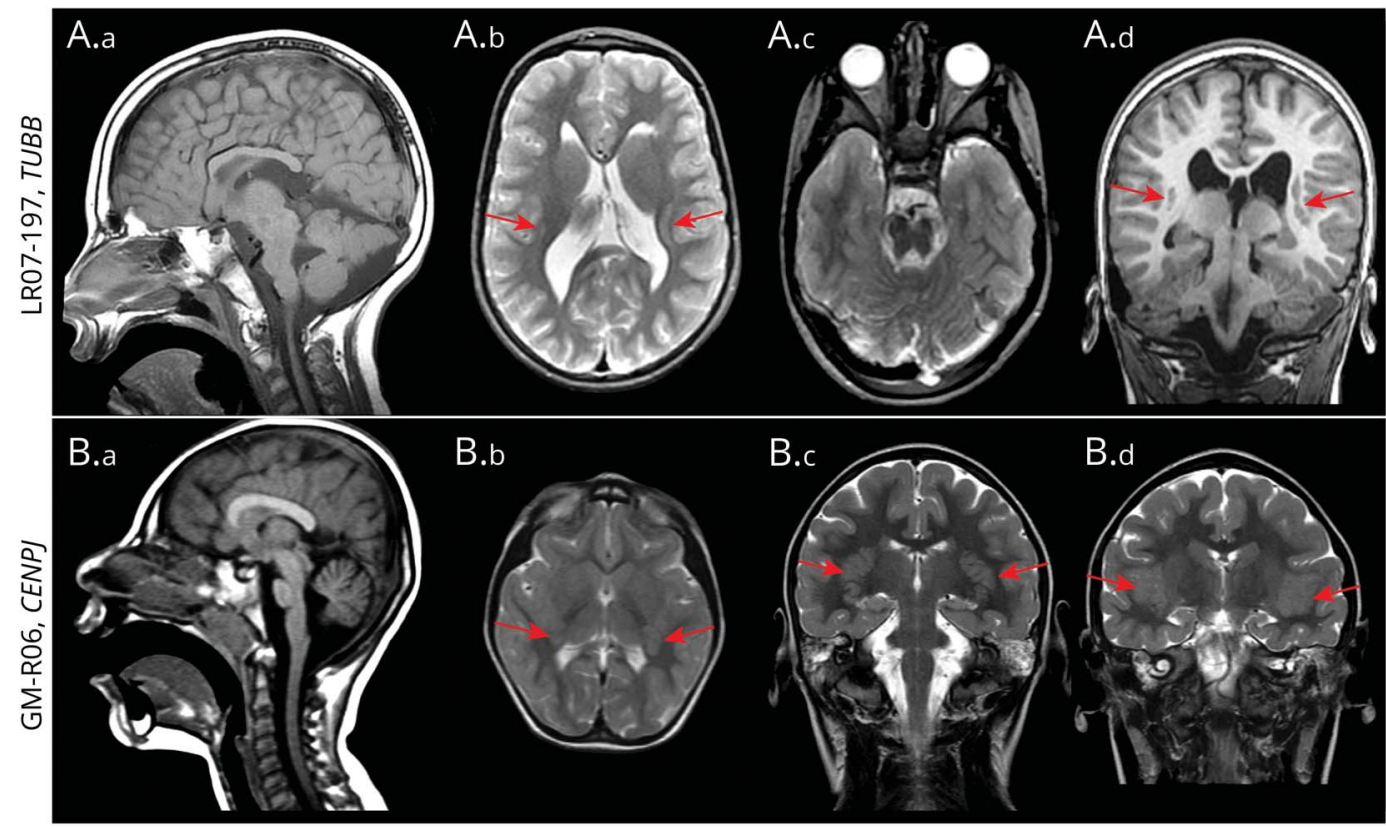

Each row depicts images from the same patient. (A.a, B.a) Midline sagittal. (A.b, B.b) Axial at the level of the basal ganglia. (A.c) Axial. (B.c) Coronal. (A.d, B.d) Coronal. LR07-197 has bilateral, left larger than right, peritrigonal optic pathway heterotopic gray matter brain malformations (HET) (arrows: A.b and A.d). The genu of the corpus callosum and brainstem are hypoplastic (A.a), the cerebellum is dysplastic (A.c). This individual was found to have a de novo TUBB mutation c.860C >G (p.Pro287Arg). GM-R06 has bilateral peritrigonal optic pathway HET (arrows: B.b, B.c, and B.d). She also has profound microcephaly ( -11 SD). She is compound heterozygous for CENPJ mutations c.1805_1808del (p.Glu602fs) and c.289dupA (p.Thr97fs).

more lobes, with CSF-like spaces that may be prominent or subtle found within the heterotopia (figure 3 ). The overlying cortex is abnormally thin with shallow sulci and the HET always connects to the overlying cortex in at least one, but usually in multiple, locations. Sulci extending abnormally deep into the white matter are sometimes seen, although extensive cortical malformations are uncommon. They may resemble some deeply infolded HET (group 4), but curvilinear HET have a more complex morphology, making it difficult to define continuity of the CSF-like spaces with extra-axial spaces. The name curvilinear subcortical heterotopia was previously proposed by one of the authors, ${ }^{13}$ and we still consider this the best term, as it describes a band that does not form a smooth line or curve but instead swirls in different directions. The morphology is variable, and may be nodular, laminar, or lobular, even within the same individual. Any lobe can be affected either unilaterally or bilaterally. We found an equal distribution of unilateral and bilateral malformations (31 vs 30), but the brain was always asymmetrically affected. Surrounding structures (e.g., the adjacent lateral ventricle or contralateral hemisphere) may be deformed. Affected hemispheres are usually smaller than unaffected hemispheres, suggesting that both neurogenesis and neuronal migration may be affected. Also, affected areas of either or both hemispheres may be focally expanded and cross the midline, resulting in abnormal configuration (40\%) or even partial obliteration $(62 \%)$ of the ipsilateral ventricle and basal ganglia, as well as abnormalities of the corpus callosum. Ipsilateral or contralateral $\mathrm{PNH}$, separate from the nodular mass (70\%) of patients, and abnormalities of the cerebellum or posterior fossa $(36 \%)$ were also frequently observed. While only limited pathologic data are available, the size and appearance of neurons is normal in humans with curvilinear HET. ${ }^{8-10}$

\section{2d. Curvilinear heterotopia with ACC-interhemispheric cysts (always bilateral)}

We identified 5 patients with a distinct subtype of bilateral curvilinear HET combined with multiple interhemispheric cysts and ACC (figure 3). This pattern was reported in 3 individuals from a series of patients with callosal agenesis that we previously designated as "callosal agenesis with cyst type $2 c . " 25$ The similar imaging features suggest that this subtype represents a specific, recurrent pattern.

\section{2e. Transmantle columnar heterotopia}

We reserve the term transmantle columnar HET for a narrow but distinct band or wedge of gray matter that extends perpendicularly from the ependyma to the cortex (figure 3). These may be difficult to distinguish from closed lip schizencephaly, the primary distinction being absence of a piaependymal cleft and dimple at the ventricular wall. ${ }^{26}$ Also, transmantle columnar HET should not be confused with transmantle dysplasia (bottom-of-the-sulcus dysplasia), a streak of abnormal signal intensity extending from the ventricular surface up to the cortex associated with focal cortical dysplasia type $2 b^{27}$; these can be distinguished by the 
Figure 2 Representative MRI from group 2: diffuse ribbon-like heterotopic gray matter brain malformations (HET) and mesial parasagittal HET
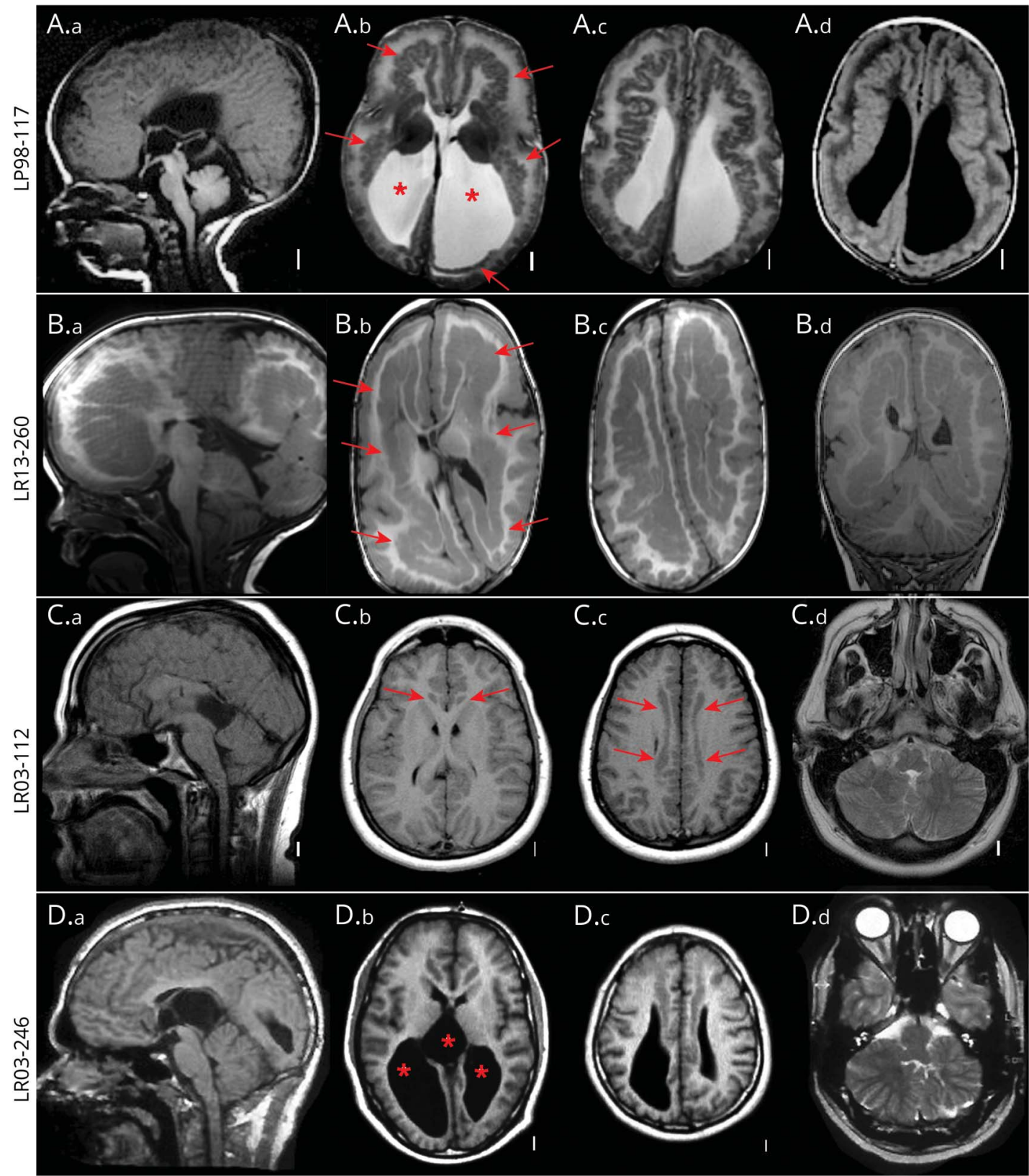

Each row depicts images from the same patient. (A.a, B.a, C.a, D.a) Midline sagittal. (A.b, B.b, C.b, D.b) Axial at the level of the basal ganglia. (A.c, B.c, C.c, D.c) Axial. (A.d, C.d, D.d) Axial. (B.d) Coronal. (A, B) LP98-117 and LR13-260 both show complete agenesis of the corpus callosum and a bilateral single undulating ribbon-like HET throughout the white matter (arrows: A.b and B.b). The cortex is polymicrogyria-like. Both individuals are megalencephalic. The lateral ventricles are enlarged in LP98-117 (asterisks: A.b). LR13-260 received a ventriculoperitoneal drain shortly after birth for treatment of hydrocephalus. A homozygous EML1 mutation was identified in LR13-260. DNA was not available for LP98-117. (C, D) LR03-112 and LR03-246 have partial agenesis of the corpus callosum and longitudinal HET in the parasagittal plane (arrows: C.b and C.c); on more upwards cuts the HET connects to the highly dysplastic mesial cortex (not shown). The cerebellum is dysplastic (C.d and D.d). Note also enlarged lateral ventricles and midline cyst in LR03-246 (asterisks: D.b). Both individuals had hearing loss. This pattern is associated with Chudley-McCullough syndrome.

signal intensity, isointense to gray matter in the transmantle HET but T2/fluid-attenuated inversion recovery hyperintense in the dysplasia.

\section{Group 3. Malformations due to abnormal neuronal migration \\ $\mathrm{PNH}$ and $\mathrm{SBH}$ were not reviewed.}

\section{Group 4. Malformations due to abnormal} postmigrational development with subcortical or transmantle component

\section{4a. Transmantle columnar and fan-like heterotopia \pm clefts}

We observed 2 patients with solid transmantle columnar and fan-like HET in addition to clefts typical of schizencephaly 
Figure 3 Representative MRI from individuals from group 2: curvilinear and transmantle heterotopic gray matter brain malformations (HET)
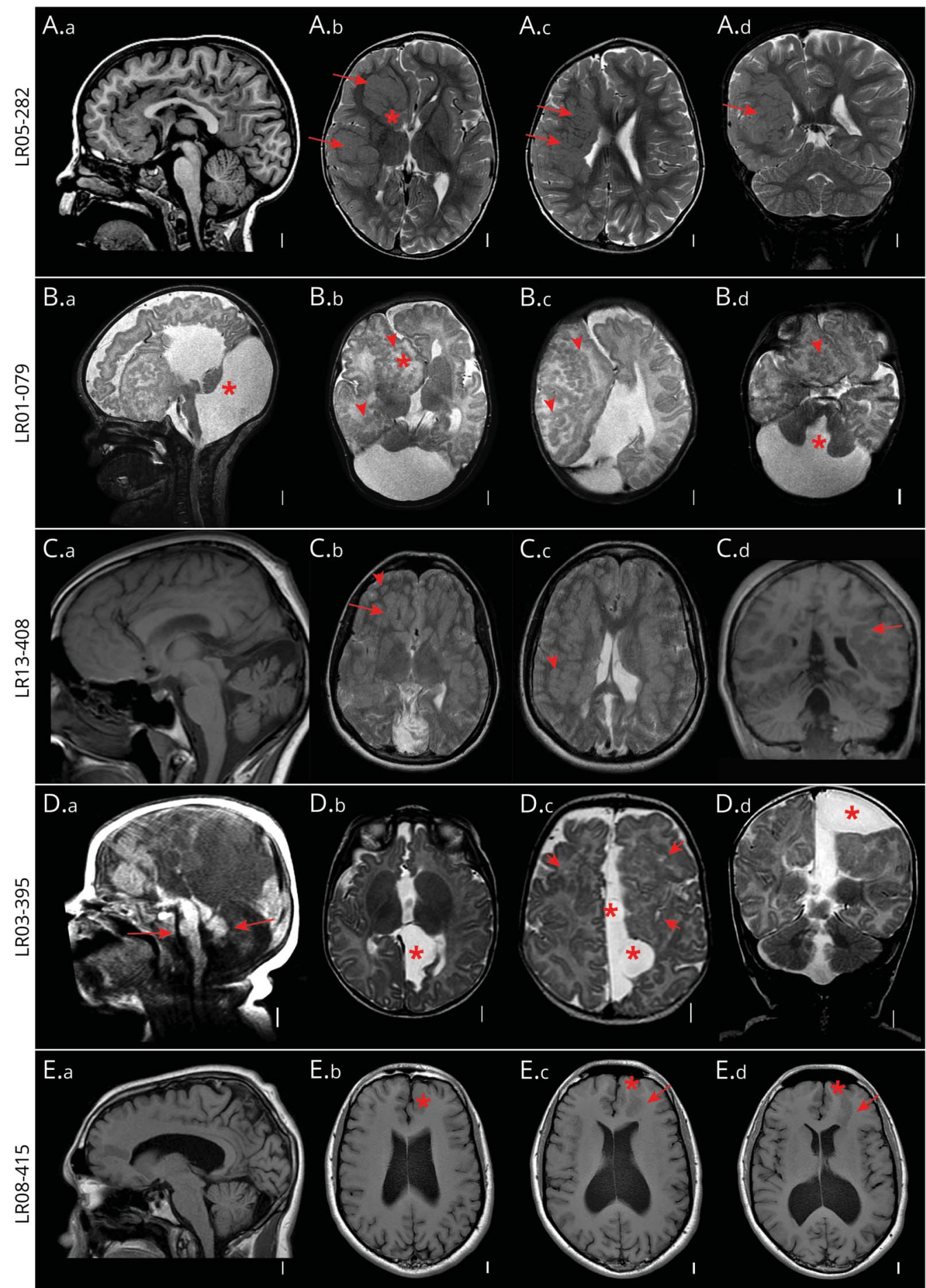

Each row depicts images from the same patient. (A.a, B.a, C.a, D.a, E.a) Midline sagittal. (A.b, B.b, C.b, D.b, E.b) Axial. (A.c, B.c, C.c, D.c, E.c) Axial. (A.d, C.d, D.d) Coronal. (B.d, E.d) Axial images. (A-C) Curvilinear subcortical band heterotopia (SUBH) with CSF-like spaces. (D) Curvilinear SUBH with agenesis of the corpus callosum (ACC)interhemispheric (IHEM) cysts. (E) Transmantle columnar HET. Images from individual LR05-282 show extensive giant HET with curvilinear CSF-like spaces in the right hemisphere (arrows: A.b-A.d). The HET connects to both the overlying cortex and the ependyma in several instances. The left hemisphere crosses the midline. The right frontal horn and right caudate nucleus cannot be identified; instead, a large heterotopic mass is seen (asterisk: A.b). LR01-079 shows HET with curvilinear and nodular SUBH (arrowheads: B.b-B.d) with extensive involvement of the right hemisphere. Also here the right frontal horn and right caudate nucleus cannot be identified (asterisk: B.b). The cerebellum is hypoplastic with a Dandy-Walker configuration (asterisk: B.a and B.d). LR13-408 has extensive involvement of both hemispheres with both curvilinear HET connecting to the cortex and multiple nodular SUBH (examples: C.a-C.d). LRO3-395: bilateral asymmetric HET with IHEM. The cysts are denoted with asterisks (D.b-D.d). Note also ACC and hypoplastic pons and cerebellar vermis (arrow: D.a). CSF-like spaces are identifiable (arrowheads: D.c). LR08-415: transmantle columnar HET in the left frontal lobe (arrows: E.c and E.d). The overlying cortex is dysplastic (asterisks: E.b, E.c, E.d), and the lateral ventricles are mildly enlarged. 
(figure 4). In both, 2 or more distinct transmantle HET or clefts were seen in each hemisphere. One boy (LR01-016a2) had a brother with bilateral severe open-lip schizencephaly and was previously published as a rare form of familial schizencephaly, although the EMX2 sequence variant reported is highly unlikely to be pathogenic. ${ }^{28}$

\section{4c-4e. Deeply infolded HET}

These groups are characterized by (1) extension of 2 opposing cortices separated by CSF into the deep white matter well beyond the usual cortical-white matter boundary but in clear continuity with the overlying cortex, (2) mild thickening $(5-10 \mathrm{~mm})$ and irregularity of all or most of the infolded cortex consistent with polymicrogyria, and (3) clear connection of CSF spaces with overlying sulci and subarachnoid space. While the CSF spaces lined by dysplastic cortex resemble the clefts observed in schizencephaly, and we cannot exclude the possibility that they are formed by related processes, they do not communicate with the lateral ventricles and have a branching pattern typical of sulci.

We identified 10 individuals with infolding patterns of similar morphology and variable, posterior predominant, localization, a malformation that we previously described as "bilateral parasagittal parietooccipital polymicrogyria." ${ }^{29}$ This deeply infolded HET-parieto-occipital subtype (4c)predominately affected parietal or occipital regions but the frontal and temporal lobe were sometimes involved as well (figure 4). The infolding always involved the mesial parietal and occipital cortex, and in several patients a strictly mesial malformation was observed. In its most complete form, the HET extends from the mesial parietal and occipital region behind the splenium of the corpus callosum, around the occipital horn and trigone of the lateral ventricles, and to the posterior perisylvian region. Other brain structures were preserved or only mildly involved in most individuals. The corpus callosum was thin or incompletely formed, but none had complete agenesis; all had normal deep gray nuclei except for one individual with globular-shaped thalami and 3 had mild cerebellar abnormalities with hypoplasia of the cerebellar hemispheres, vermis, or both. This rare malformation was previously found in $11 / 328$ individuals with polymicrogyria. ${ }^{16}$

In the parasagittal subtype (4d), a continuous band of deeply infolded HET that resembles polymicrogyric cortex is seen. It is located parallel to the midsagittal plane, extending from the antero-lateral to postero-medial cortex and deeply into the white matter to touch the ventricular walls (figure 4). The HETs were bilateral and highly symmetric in appearance and best recognized in axial and coronal planes. Although abnormalities of the corpus callosum were observed, none of the 6 patients had complete agenesis of the corpus callosum. Of note, all patients had normal deep gray nuclei and a normal cerebellum. We were able to identify only one previous mention of this subtype: a single image from one of our patients (LR01-283) was presented as bilateral superior parasagittal polymicrogyria, and defined as unilateral or bilateral "bands" of polymicrogyria lining abnormal lateral parasagittal sulci. ${ }^{16,30}$ We collected clinical data on all 6 patients with this subtype. They all presented with early motor delay; 4 developed spasticity, and 1 had a normal neurologic examination at 10 years. Three had intellectual disability, and 2 were cognitively normal. Seizures that began during puberty were seen in 3 individuals. The other 3 , without seizures, had not yet reached puberty. For 3 individuals, OFC data were available and all had microcephaly ranging from -3 to $-5 \mathrm{SD}$. One discordant and 2 concordant twins were included.

In the remaining 3 patients with deep infolding (deeply infolded HET - other subtypes, 4e), HET occurred in a different location, but all involved the frontal lobes.

\section{Group 5. HET with bilateral complex patterns}

\section{5a. Microventriculy (holoprosencephaly-like)}

This very rare malformation presents with distinctive abnormalities of HET, absent or very small lateral ventricles, unseparated thalami, and encephalocele (figure 5). The HET consists of seemingly disorganized deeply infolded fissures lined with dysplastic cortex, combined with vessels, white matter, and CSF. Both patients also had cerebellar dysplasia. Absence of the ventricles (aventriculy) in combination with absent separation of midline structures was first described by Garfinkle in $1996 .{ }^{31}$ Since then, only 4 further patients have been reported. $^{32-35}$ HET were present in at least 3 of these patients. It shares several features with the brain-in-brain malformation (see below), except for the absence of a midline mass.

\section{5b. Brain-in-brain malformation}

This complex malformation was originally defined as a midline mass of dysplastic cortex with holoprosencephalic features. ${ }^{36}$ We classified 4 patients with a midline mass of gray and white matter signal intensity as brain-in-brain malformation. Two of these patients also had microventriculy and 3 had continuity of cerebral structures across the midline (the middle interhemispheric fusion subtype of holoprosencephaly, unseparated thalami, or mesencephalosynapsis) (figure 5). Another key feature was presence of an encephalocele, or turricephaly with high parietal interhemispheric cysts. Also, CSF-like spaces and blood vessels were sometimes seen. We identified one patient who had HET and a midline mass with signal intensities suggesting a mix of gray and white matter, but with normal midline structures. This patient may possibly reflect the milder end of the spectrum. In hindsight, the patient described by Garfin$\mathrm{kle}^{31}$ also shows a midline mass and could possibly be classified as brain-in-brain malformation. Shaw and Alvord ${ }^{35}$ published pathology studies of 3 patients with "global cerebral dysplasia," which in hindsight could also be classified as brainin-brain malformations. These patients had large central masses without distinguishable deep gray nuclei. The ventricular system of one fetal case was filled with disorganized germinal cells that the authors presumed to be dislocated 
Figure 4 Representative MRI from individuals from group 3: transmantle columnar and fan-like heterotopic gray matter brain malformations (HET) and deeply infolded HET
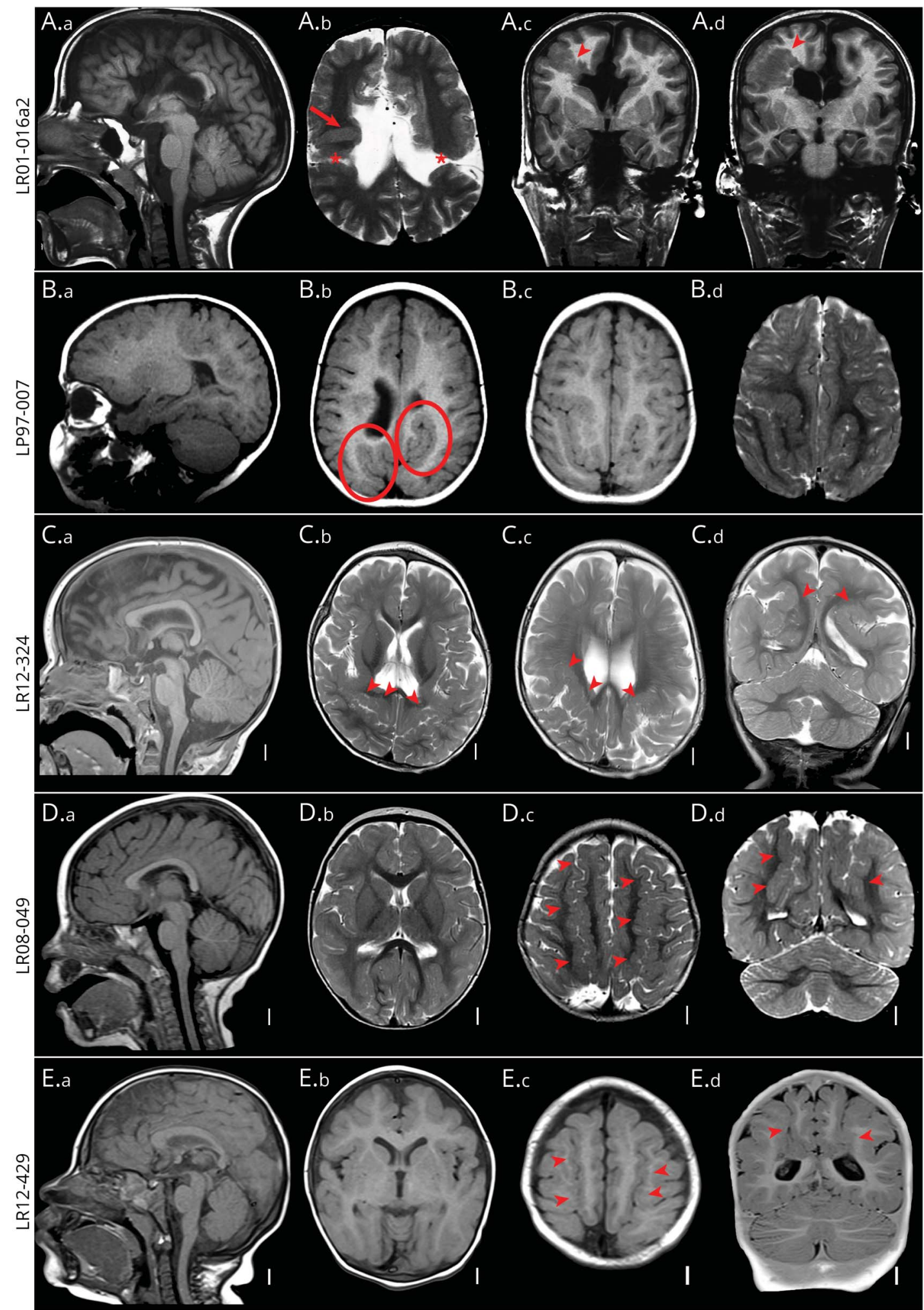

Each row depicts images from the same patient. (A.a, B.a, C.a, D.a, E.a) Midline sagittal. (A.b, C.b, D.b, E.b) Axial at the level of the basal ganglia. (B.b) Axial. (A.c) Coronal. (B.c, C.c, D.c, E.c) Axial. (A.d, C.d, D.d, E.d) Coronal. (B.d) Axial. (A) Partial agenesis of the corpus callosum, transmantle columnar subcortical band heterotopia (SUBH) (arrow: A b) and fan-like SUBH (arrowhead: A c and A d) and bilateral clefts (asterisks: A b). (B, C) Deeply infolded HET-parieto-occipital subtype was identified in LP97007 and LR12-324, originating posteriorly in the perisylvian areas with an oblique orientation relative to the sagittal plane (circles [B.b] and arrowheads [C.b-C.d]). (D, E) Deeply infolded-parasagittal subtype. Images show a highly similar pattern of bilateral parasagittal deep infolded HET touching the ependyma (arrowheads: D.c, D.d, E.c, E.d). Both individuals are microcephalic (occipital frontal circumference -3 SD and -5 SD, respectively). Other brain structures are relatively preserved. 
Figure 5 Representative MRI from individuals from group 4: microventriculy and brain-in-brain malformation
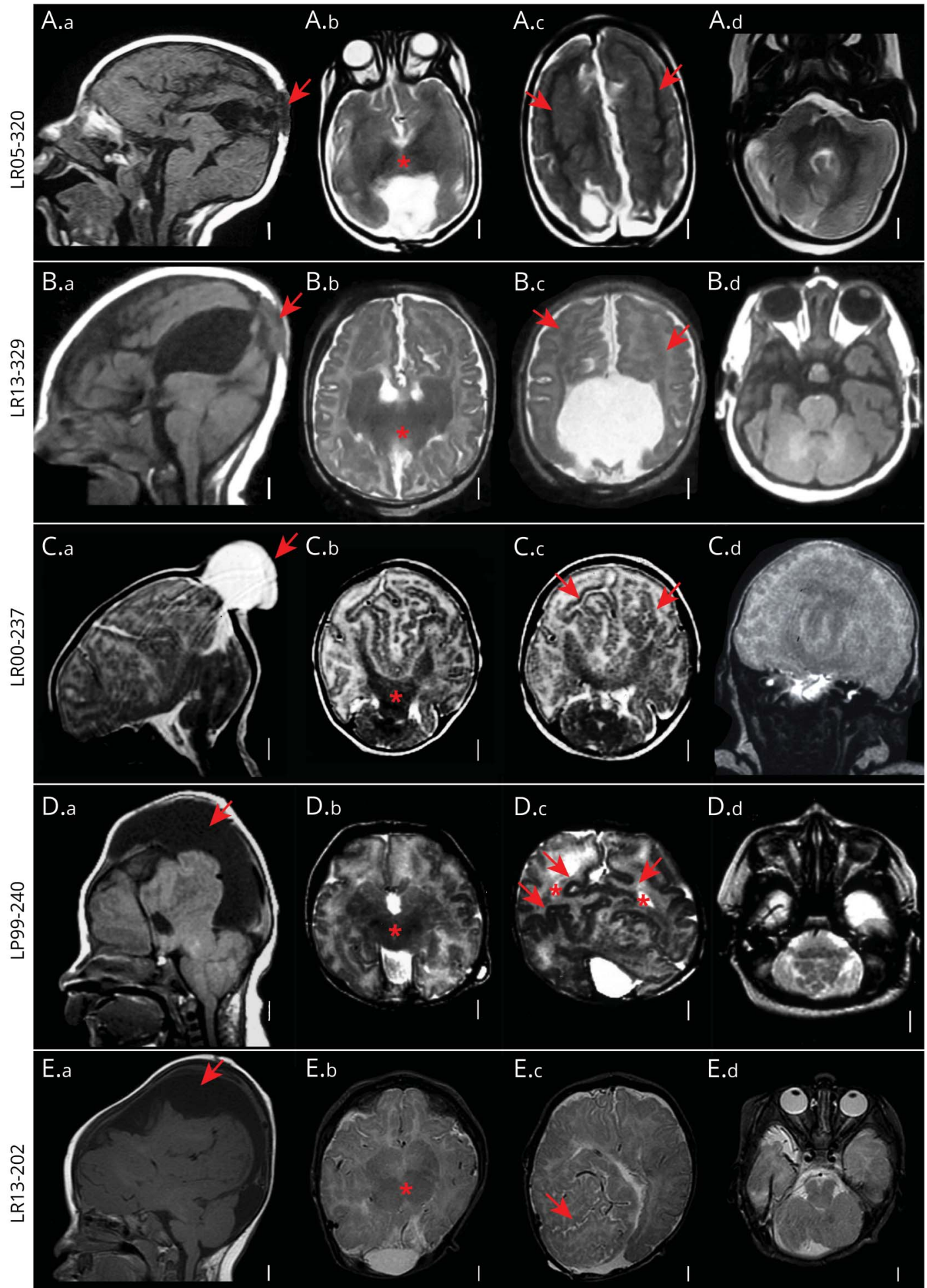

E.d

(A.a, B.a, C.a, D.a, E.a) Midline sagittal. (A.b, B.b, C.b, D.b, E.b) Axial at the level of the basal ganglia. (A.c, B.c, C.c, D.c, E.c) Axial. (A.d, B.d, D.d, E.d) Axial images of cerebellum. (C.d) Coronal. (A, B): Microventriculy with heterotopic gray matter brain malformations (HET). (C-E) Brain-in-brain malformation. The latter has similarities to microventriculy and has in addition a midline mass of gray and white matter signal intensity. We did not identify normal lateral ventricles (LV) in any individual. In LP99-240, however, CSF-filled spaces were seen in the region where the LV are expected (asterisks: D.c). The HET are bilateral and resemble disorganized sulci deeply infiltrating the white matter (arrows: D.c). LR00-237, LR05-320, and LR13-329 have high occipital encephalocele, and LR05-320 and LR13-202 have turricephaly with high parietal interhemispheric cyst (arrows: A.a, B.a, C.a, D.a, E.a). Thalamic fusion is suspected in all (asterisks: A.b, B.b, C.b, D.b, E.b) and in addition, alobar holoprosencephaly in LR00-237 and middle interhemispheric fusion in LR99-240 (C.c and D.c). The cerebellum is hypoplastic in all and severe dysplastic in all but LR13-329 (A.d, C.b, C.c, D.d, E.d). 
from the subependymal matrix. ${ }^{35}$ The cause of these rare and complex malformations remains to be determined.

\section{5c. Complex chaotic HET}

This small group consists of 2 patients with a complex and highly disorganized subcortical malformation with diffuse and bilateral involvement. The key features consist of both gyriform and nodular HET along with areas of CSF "inclusions" lined by gray matter. Multiple HET connect to the cortex. These 2 patients may represent either distinct entities or more extensive forms of the curvilinear HET.

\section{Discussion}

We have described the imaging patterns and associated clinical features of 107 patients with rare brain malformations predominantly characterized by heterotopic, predominant subcortical localization of gray matter. These also include several additional complex MCD with deeply infolded gyri that predominately occupy subcortical space. We have divided them into subgroups relying primarily on imaging features as only limited pathologic data are available and few underlying genes are known. As expected from literature reports, by far the largest group in our cohort consisted of curvilinear HET with CSF-like spaces (62\%), discussed in more detail below. In planning this analysis, we had expected to find mostly localized focal-segmental HET, but also found many bilateral and diffuse forms.

Previous studies of SUBH focused primarily on associated neurologic symptoms. Indeed, abnormal cognitive or motor development and epilepsy were present in the majority of patients. However, we also observed a high frequency of extraCNS malformations (46\%).

Given the paucity of data available regarding the underlying causes of SUBH, our placement of the various subtypes into our existing MCD classification system must be considered tentative, and will need to be revised as knowledge advances. However, detailed analysis of our data and the literature provides support for both genetic and extrinsic causes for different types of HET (discussed below).

With 61 patients and 5 additional patients with interhemispheric cysts and ACC, we report by far the largest cohort of curvilinear HET to date. Previous reports on this malformation mostly involved single patient reports or small series. $^{8-10,12,14,37}$ The clinical spectrum regarding development was very broad. Thirteen individuals of our cohort had normal cognitive and motor development, which seems remarkable judging from the size and extent of the malformation. The largest reported series described imaging and clinical features of 24 patients, and in this study, all had seizures and almost all had pyramidal signs, usually contralateral to the brain lesion. ${ }^{13}$ No correlation between clinical outcome and radiologic features was found in that study.
Another report compared 9 patients with PNH only to 9 with both $\mathrm{PNH}$ and unilateral SUBH. ${ }^{37}$ The latter group had lower average IQ scores and higher incidence of developmental delay and neurologic signs compared to the PNH only group. In previous reports, several different terms have been used for this group, including giant subcortical nodular heterotopia, ${ }^{9}$ focal subcortical heterotopia, ${ }^{38}$ massive heterotopia, ${ }^{7}$ subcortical nodular heterotopia, ${ }^{37}$ and curvilinear transmantle heterotopia. ${ }^{1}$ Of note, curvilinear heterotopia may have a multinodular appearance at first glance (see, for example, figure 3, LR01-079). However, high-resolution images in multiple planes show a curvilinear morphology. A few additional nodules may be seen surrounding the main body of the curvilinear HET. In contrast to previous reports, we did not find an increase of patients with unilateral curvilinear HET vs bilateral. $^{13,14,37}$

Strong support exists for genetic causes, particularly for the rare HET that are consistently symmetric (groups 1-2), as several genes have recently been identified (table 2). All of these HET are bilateral and solid, and are frequently observed with either microcephaly or megalencephaly. Several of these genes code for proteins that localize to the mitotic spindle and microtubules. The CENPJ gene encodes a centrosomal protein with tubulin-dimer binding activity. ${ }^{39}$ KATNB1 together with KATNA1 forms the microtubule-severing protein katanin, which localizes to the centrosome. ${ }^{21}$ TUBB encodes a $\beta$ tubulin, and $\beta$-tubulins together with $\alpha$-tubulins form the core of the microtubules. $^{20}$ This association is not surprising because both primary microcephalies as well as multiple MCD with complex brain malformations have been linked to similar mechanisms. $^{40,41}$

In humans, 2 genes have been identified that cause large symmetric HET without a connection to the cortex-GPMS2 and EML1. Biallelic (homozygous or compound heterozygous) mutations of EML1 result in megalencephaly with diffuse ribbon-like $\mathrm{SUBH}$ in humans and comparable large symmetric SUBH in mice, ${ }^{22}$ while biallelic loss of GPMS2 results in symmetric parasagittal SUBH in humans and a subtle developmental abnormality in mice. ${ }^{24}$ Both mouse models demonstrate increased numbers of neural progenitor cells - both Pax6+ radial glia cells (neural stem cells) and Tbr2+ intermediate progenitor cells - proliferating in ectopic locations throughout the cortical wall. ${ }^{22,42}$

Curvilinear HET accounted for more than half of the patients in this study. We find it striking that no genetic diagnosis was known for any patient, nor did we encounter any sibling recurrences. The segmental involvement could be the result of a postzygotic mutation. Indeed 2 unrelated patients have been reported with germline BRCA1 mutations and SUBH, leading the authors to propose a postzygotic mutation on the second allele as a cause for the brain malformation. ${ }^{38,43}$ However, both patients were born twins, which would also support fetal vascular disruption. Pathologic data are scarce, with only 3 anecdotal reports available, which do not mention 
abnormal cellular morphology. ${ }^{8-10}$ In our series of patients with curvilinear HET, 1/61 had absent right internal carotid artery, 2/61 had absence of an arm, and a different 2/61 had a history of twinning. Published reports of curvilinear HET describe a history of twinning, near miscarriage, or prenatal trauma. ${ }^{7,8,11,37,38,43}$ In our patients with deeply infolded subcortical malformations, $4 / 6$ had twinning or jejunal atresia in our parasagittal group, while $2 / 6$ had twinning or heavy maternal bleeding during early pregnancy in our parieto-occipital group. While these numbers are small, the rate of twinning appears to be higher than the overall twin birth rate of 33 per $1,000 .{ }^{44}$ Numerous published reports demonstrate that prenatal vascular disruption is associated with schizencephaly or polymicrogyria as well as some forms of HET. ${ }^{45-50}$ In several of these children, the malformation was accompanied by heterotopia consisting of nodules or strands of immature neurons distributed in a fan-like pattern from the ependymal zone through the subcortical white matter and up to the dysplastic cortex and molecular layer.

This study represents the first effort to define and describe the heterogeneous group of malformations associated with subcortical heterotopia or deep subcortical infolding and increase awareness of its frequency and complexity. Although the causes of most of these complex anomalies are unknown, increased awareness of them will lead to better recognition of affected individuals and stimulate scientific research regarding their causes, manifestations, and, eventually, therapeutic options. Based on the high frequency of extra-CNS malformations, we recommend a full physical examination focusing on congenital anomalies, an ophthalmologic examination, and renal ultrasound.

This study and the associated literature review show that solid, symmetric heterotopia are often genetic with a recurrence risk as high as $25 \%$; however, these subtypes are the least frequent among the HET. We hypothesize that (1) some unilateral and asymmetric HET result from postzygotic mutations and (2) some forms of HET are caused by prenatal injury during the fetal period, especially vascular disruption.

Elucidating the pathogenesis underlying HET may enable an improved understanding of their causes, along with a development of targeted therapies. As this classification is based on imaging appearance, it will need revision as underlying genes and pathways are discovered. Meanwhile, this classification will not just be useful to the clinician, but also to the genetic researcher, as correct phenotype assignment is essential when interpreting genetic variants.

\section{Author contributions}

Renske Oegema: drafting/revising the manuscript, data acquisition, study concept or design, analysis or interpretation of data, accepts responsibility for conduct of research and final approval, acquisition of data, statistical analysis, study supervision, obtaining funding. A. James Barkovich: drafting/revising the manuscript, data acquisition, analysis or interpretation of data, accepts responsibility for conduct of research and final approval, acquisition of data, study supervision. Grazia M.S. Mancini: data acquisition, analysis or interpretation of data, accepts responsibility for conduct of research and final approval. Renzo Guerrini: drafting/ revising the manuscript, data acquisition, study concept or design, analysis or interpretation of data, accepts responsibility for conduct of research and final approval, obtaining funding. William B. Dobyns: drafting/revising the manuscript, data acquisition, study concept or design, analysis or interpretation of data, accepts responsibility for conduct of research and final approval, study supervision, obtaining funding, study funding, no targeted funding reported.

\section{Acknowledgment}

The authors thank all the individuals and their families and the referring physicians for their contributions to this study. R.O., A.J.B., G.M.S.M., R.G., and W.B.D. are members of the Neuro-MIG network (COST Action CA16118) on brain malformations.

\section{Study funding}

No targeted funding reported.

\section{Disclosure}

R. Oegema was supported by an EMBO short-term fellowship and a Simonsfonds grant from the Dutch Society of Human Genetics. A. Barkovich reports no disclosures relevant to the manuscript. G. Mancini was supported by the Erasmus MC-Mrace grant project number 104673 and NWO/ZonMW Top grant number 91217045. R. Guerrini was supported by the European Union Seventh Framework Programme FP7/2007-2013 under the project DESIRE, grant agreement number 602531. W. Dobyns was supported by the National Institute of Neurologic Disorders and Stroke of the NIH under award numbers R01NS050375, R01NS058721, and R01NS092772. Go to Neurology.org/N for full disclosures.

\section{Publication history}

Received by Neurology January 9, 2019. Accepted in final form May 3, 2019.

\section{References}

1. Barkovich AJ, Guerrini R, Kuzniecky RI, Jackson GD, Dobyns WB. A developmental and genetic classification for malformations of cortical development: update 2012. Brain 2012;135:1348-1369.

2. Harvey AS, Cross JH, Shinnar S, Mathern GW; ILAE Pediatric Epilepsy Surgery Survey Taskforce. Defining the spectrum of international practice in pediatric epilepsy surgery patients. Epilepsia 2008;49:146-155.

3. Hunter A. Brain. In: Stevenson RE, Hall JG, Goodman R, eds. Human Malformations and Related Anomalies. Oxford: Oxford University Press; 1993:1-52.

4. Jacobs MP, Fischbach GD, Davis MR, et al. Future directions for epilepsy research. Neurology 2001;57:1536-1542.

5. Kuzniecky R, Murro A, King D, et al. Magnetic resonance imaging in childhood intractable partial epilepsies: pathologic correlations. Neurology 1993;43: 681-687.

6. Mischel PS, Nguyen LP, Vinters HV. Cerebral cortical dysplasia associated with pediatric epilepsy: review of neuropathologic features and proposal for a grading system. J Neuropathol Exp Neurol 1995;54:137-153.

7. Kuzniecky R, Gilliam F, Faught E. Discordant occurrence of cerebral unilateral heterotopia and epilepsy in monozygotic twins. Epilepsia 1995;36:1155-1157. 
8. Novegno F, Battaglia D, Chieffo D, et al. Giant subcortical heterotopia involving the temporo-parieto-occipital region: a challenging cause of drug-resistant epilepsy. Epilepsy Res 2009;87:88-94.

9. Battaglia G, Arcelli P, Granata T, et al. Neuronal migration disorders and epilepsy: a morphological analysis of three surgically treated patients. Epilepsy Res 1996;26:49-58.

10. Poduri A, Golja A, Riviello JJ Jr, Bourgeois BF, Duffy FH, Takeoka M. A distinct asymmetrical pattern of cortical malformation: large unilateral malformation of cortical development with contralateral periventricular nodular heterotopia in three pediatric cases. Epilepsia 2005;46:1317-1321.

11. Preul MC, Leblanc R, Cendes F, et al. Function and organization in dysgenic cortex: case report. J Neurosurg 1997;87:113-121.

12. Raghavendra S, Krishnamoorthy T, Ashalatha R, Nayak SD, Radhakrishnan K Hemimegalencephalic appearance of normal hemisphere in unilateral heterotopia and absent corpus callosum. Epilepsy Behav 2006;9:363-366.

13. Barkovich AJ. Morphologic characteristics of subcortical heterotopia: MR imaging study. AJNR Am J Neuroradiol 2000;21:290-295.

14. Barkovich AJ. Subcortical heterotopia: a distinct clinicoradiologic entity. AJNR Am J Neuroradiol 1996;17:1315-1322.

15. Takanashi J, Barkovich AJ, Clegg NJ, Delgado MR. Middle interhemispheric variant of holoprosencephaly associated with diffuse polymicrogyria. AJNR Am J Neuroradiol 2003;24:394-397.

16. Leventer RJ, Jansen A, Pilz DT, et al. Clinical and imaging heterogeneity of polymicrogyria: a study of 328 patients. Brain 2010;133:1415-1427.

17. Di Donato N, Chiari S, Mirzaa GM, et al. Lissencephaly: expanded imaging and clinical classification. Am J Med Genet A 2017;173:1473-1488.

18. Dobyns WB. The clinical patterns and molecular genetics of lissencephaly and subcortical band heterotopia. Epilepsia 2010;51(suppl 1):5-9.

19. Parrini E, Ramazzotti A, Dobyns WB, et al. Periventricular heterotopia: phenotypic heterogeneity and correlation with Filamin A mutations. Brain 2006;129:1892-1906.

20. Breuss M, Heng JI, Poirier K, et al. Mutations in the beta-tubulin gene TUBB5 cause microcephaly with structural brain abnormalities. Cell Rep 2012;2:1554-1562.

21. Mishra-Gorur K, Caglayan AO, Schaffer AE, et al. Mutations in KATNB1 cause complex cerebral malformations by disrupting asymmetrically dividing neural progenitors. Neuron 2014;84:1226-1239.

22. Kielar M, Tuy FP, Bizzotto S, et al. Mutations in Eml1 lead to ectopic progenitors and neuronal heterotopia in mouse and human. Nat Neurosci 2014;17:923-933.

23. Shaheen R, Sebai MA, Patel N, et al. The genetic landscape of familial congenital hydrocephalus. Ann Neurol 2017;81:890-897.

24. Doherty D, Chudley AE, Coghlan G, et al. GPSM2 mutations cause the brain malformations and hearing loss in Chudley-McCullough syndrome. Am J Hum Genet 2012;90:1088-1093.

25. Barkovich AJ, Simon EM, Walsh CA. Callosal agenesis with cyst: a better understanding and new classification. Neurology 2001;56:220-227.

26. Barkovich AJ, Kjos BO. Schizencephaly: correlation of clinical findings with MR characteristics. AJNR Am J Neuroradiol 1992;13:85-94.

27. Barkovich AJ, Kuzniecky RI, Bollen AW, Grant PE. Focal transmantle dysplasia: a specific malformation of cortical development. Neurology 1997;49:1148-1152.

28. Granata T, Farina L, Faiella A, et al. Familial schizencephaly associated with EMX2 mutation. Neurology 1997;48:1403-1406.

29. Guerrini R, Dubeau F, Dulac O, et al. Bilateral parasagittal parietooccipital polymicrogyria and epilepsy. Ann Neurol 1997;41:65-73.
30. Barkovich AJ, Hevner R, Guerrini R. Syndromes of bilateral symmetrical polymicrogyria. AJNR Am J neuroradiology 1999;20:1814-1821.

31. Garfinkle WB. Aventriculy: a new entity? AJNR Am J neuroradiology 1996;17: 1649-1650.

32. Ishak GE, Dempsey JC, Shaw DW, et al. Rhombencephalosynapsis: a hindbrain malformation associated with incomplete separation of midbrain and forebrain, hydrocephalus and a broad spectrum of severity. Brain 2012;135:1370-1386.

33. Sener RN. Schizencephaly and congenital cytomegalovirus infection. J Neuroradiol 1998;25:151-152.

34. Kumar S, Jaiswal AK, Rastogi M. Aventriculi associated with holoprosencephaly. J Clin Neurosci 2006;13:378-380.

35. Shaw CM, Alvord EC Jr. Global cerebral dysplasia due to dysplasia and hyperplasia of periventricular germinal cells. J Child Neurol 1996;11:313-320.

36. Widjaja E, Massimi L, Blaser S, Di Rocco C, Raybaud C. Midline "brain in brain": an unusual variant of holoprosencephaly with anterior prosomeric cortical dysplasia. Childs Nerv Syst 2007;23:437-442.

37. Dubeau F, Tampieri D, Lee N, et al. Periventricular and subcortical nodular heterotopia: a study of 33 patients. Brain 1995;118:1273-1287.

38. Eccles D, Bunyan D, Barker S, Castle B. BRCA1 mutation and neuronal migration defect: implications for chemoprevention. J Med Genet 2005;42:e42.

39. Tang CJ, Fu RH, Wu KS, Hsu WB, Tang TK. CPAP is a cell-cycle regulated protein that controls centriole length. Nat Cell Biol 2009; 11:825-831.

40. Alcantara D, O’Driscoll M. Congenital microcephaly. Am J Med Genet C Semin Med Genet 2014;166C:124-139.

41. Mutch CA, Poduri A, Sahin M, Barry B, Walsh CA, Barkovich AJ. Disorders of microtubule function in neurons: imaging correlates. AJNR Am J Neuroradiol 2016; 37:528-535.

42. Konno D, Shioi G, Shitamukai A, et al Neuroepithelial progenitors undergo LGNdependent planar divisions to maintain self-renewability during mammalian neurogenesis. Nat Cell Biol 2008;10:93-101.

43. Eccles DM, Barker S, Pilz DT, Kennedy C. Neuronal migration defect in a BRCA1 gene carrier: possible focal nullisomy?. J Med Genet 2003;40:e24.

44. Martin JA, Hamilton BE, Osterman MJ. Three Decades of Twin Births in the United States, 1980-2009. NCHS Data Brief 2012:1-8.

45. Baker EM, Khorasgani MG, Gardner-Medwin D, Gholkar A, Griffiths PD. Arthrogryposis multiplex congenita and bilateral parietal polymicrogyria in association with the intrauterine death of a twin. Neuropediatrics 1996;27: $54-56$.

46. Larroche JC, Girard N, Narcy F, Fallet C. Abnormal cortical plate (polymicrogyria), heterotopias and brain damage in monozygous twins. Biol Neonate 1994;65: 343-352.

47. Lenti C, Triulzi F. Discordant clinical and neuroradiological features of congenital bilateral perisylvian syndrome in monozygotic female twins. Ital J Neurol Sci 1996;17: 287-290

48. Sugama S, Kusano K. Monozygous twin with polymicrogyria and normal co-twin. Pediatr Neurol 1994;11:62-63.

49. Van Bogaert P, Donner C, David P, Rodesch F, Avni EF, Szliwowski HB. Congenital bilateral perisylvian syndrome in a monozygotic twin with intra-uterine death of the co-twin. Dev Med Child Neurol 1996;38:166-170.

50. Cavallin M, Mine M, Philbert M, et al. Further refinement of COL4A1 and COL4A2 related cortical malformations. Eur J Med Genet 2018;61:765-772. 


\section{Neurology}

\section{Subcortical heterotopic gray matter brain malformations: Classification study of 107 individuals \\ Renske Oegema, A. James Barkovich, Grazia M.S. Mancini, et al.}

Neurology 2019;93;e1360-e1373 Published Online before print September 4, 2019

DOI 10.1212/WNL.0000000000008200

This information is current as of September 4, 2019

Updated Information \& Services

References

Citations

Subspecialty Collections

Permissions \& Licensing

Reprints including high resolution figures, can be found at: http://n.neurology.org/content/93/14/e1360.full

This article cites 48 articles, 11 of which you can access for free at: http://n.neurology.org/content/93/14/e1360.full\#ref-list-1

This article has been cited by 1 HighWire-hosted articles: http://n.neurology.org/content/93/14/e1360.full\#\#otherarticles

This article, along with others on similar topics, appears in the following collection(s):

\section{All Genetics}

http://n.neurology.org/cgi/collection/all_genetics

Developmental disorders

http://n.neurology.org/cgi/collection/developmental_disorders

\section{MRI}

http://n.neurology.org/cgi/collection/mri

Information about reproducing this article in parts (figures,tables) or in its entirety can be found online at:

http://www.neurology.org/about/about_the_journal\#permissions

Information about ordering reprints can be found online:

http://n.neurology.org/subscribers/advertise

Neurology ${ }^{\circledR}$ is the official journal of the American Academy of Neurology. Published continuously since 1951, it is now a weekly with 48 issues per year. Copyright Copyright ( 2019 The Author(s). Published by Wolters Kluwer Health, Inc. on behalf of the American Academy of Neurology.. All rights reserved. Print ISSN: 0028-3878. Online ISSN: 1526-632X.

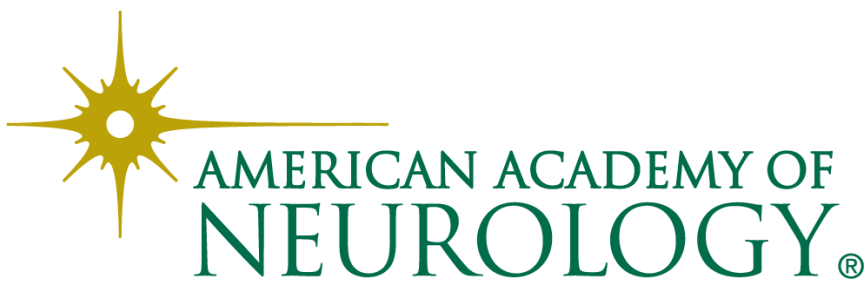

